\title{
A proximidade de um Parque Paleontológico estimulando o conhecimento entre estudantes da Educação Básica Brasileira
}

\author{
The proximity of a Paleontological Park encouraging knowledge among students of Brazilian Basic Education
}

\author{
Guilherme Cordeiro da Graça de Oliveira, Edwaldo Oliva , Ausenda Cáceres Balbino, Luis Otávio Rezende Castro, Fátima Suel Neto Ribeiro \\ Inst. Química, Univ. Fed. Rio de Janeiro, Av. Athos da Silveira Ramos, 149 Centro de Tecnologia, bloco A, sala 408. Rio de Janeiro, Brasil.

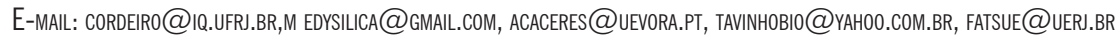

Abstract: This paper deals with teaching of Paleontology in Brazilian Basic Education. The main objective of the study was to investigate if the proximity of the school to a paleontological park - including all the educational possibilities entailed - could result in greater knowledge about paleontology. The methodology used is characterized as a quantitative and exploratory survey. Questionnaires were applied regarding basic knowledge about the subject. The results obtained suggest that the proximity of the park influenced students' paleontological knowledge. Suggested ways of using the park as an effective non-formal setting for teaching and learning of paleontological concepts are discussed.

\section{Manuscrito:}

Recebido: 19/02/2019

Corrigido: 21/08/2019

Aceito: 12/09/2019

Citação: Oliveira, G. C. G. ,Oliva, E., Balbino, A. C. , Castro, L. O. R. 2019. A proximidade de um Parque Paleontológico estimulando o conhecimento entre estudantes da Educação Básica Brasileira. Terræ Didatica, 15, 1-8, e19034. doi: $10.20396 /$ td.v15i0.8654372

Palavras-chave:Educação Básica. Ensino de Paleontologia.Parque Paleontológico de Itaboraí.

\section{Introdução}

A Paleontologia é uma ciência multidisciplinar e seus estudos transitam na interface Geociências e Ciências Biológicas. Através da interpretação de registros fósseis os pesquisadores da área podem, por exemplo, inferir afirmações sobre a distribuição e evolução das espécies, a biodiversidade, o movimento dos continentes e as variações do clima, buscando a compreensão e interpretação dos achados do passado e suas consequências para o mundo atual.

No contexto educativo, seja no ambiente escolar, em trabalhos de campo ou em atividades de divulgação científica, a Paleontologia pode, por exemplo, despertar o interesse de estudantes e leigos no sentido de se obter subsídios para o conhecimento, compreensão e interpretação de temas relativos aos diferentes períodos geológicos pretéritos (Heirich et al. 2015).

Os Parâmetros Curriculares Nacionais (PCN), documento oficial brasileiro que até dezembro de 2018 regulamentou os currículos da Educação Bási- ca, não apresentam a Paleontologia como um item de estudos, mas sim atrelada a outras disciplinas. Temas ligados a Paleontologia aparecem nos PCN no capítulo sobre Ciências Naturais para o Ensino Fundamental, no eixo temático "Terra e Universo", destacando "a importância dos alunos considerarem a existência dos fósseis, seus processos de formação, as formas de vida extintas e outras muito antigas, ainda presentes no planeta" (Brasil 1998). Entretanto, em nenhum momento esse documento se faz menção à Paleontologia como a ciência que estuda os fósseis.

Nos Parâmetros Curriculares Nacionais para o Ensino Médio (PCNEM), no capítulo sobre Conhecimentos de Biologia, a Paleontologia é citada juntamente com a Embriologia, Genética e Bioquímica como "temas centrais para a compreensão dos conceitos de adaptação e seleção natural como mecanismos da evolução e a dimensão temporal e geológica do processo evolutivo" (Brasil 2000). Com relação à Base Nacional Comum Curricular (BNCC) constata-se uma completa indiferença com o tema Paleontologia, dado que o termo não é citado uma única vez (Brasil 2018). 
Quando se investiga o trabalho em sala de aula sobre conteúdos de Paleontologia, constatam-se muitos entraves que dificultam a ação docente e, por conseguinte, um aprofundamento no assunto. Despreparo e desatualização dos professores, linguagem inadequada utilizada nos textos de referência, conteúdos descontextualizados, ausência do tema nos livros didáticos, abordagem superficial nos PCN, falta de recursos didáticos são algumas razões dessa constatação apontadas na literatura (Duarte et al. 2016; Werthein \& Cunha 2005; Schwanke \& Silva 2004).

Esse artigo tem por objetivo investigar se a proximidade da escola e a consequente freqüência de seu alunado a um importante parque paleontológico favorece o conhecimento sobre temas ligados à Paleontologia. Para isso foram avaliados os livros didáticos empregados nas escolas que participaram da pesquisa e aplicado um questionário aos estudantes do Ensino Médio dessas escolas.

Contribuindo para o trabalho, são sugeridas possíveis atividades de campo capazes de motivar alunos e professores ao ensino e aprendizagem, reforçando e aprofundando os conteúdos básicos da Paleontologia.

\section{A Educação Básica Brasileira e a Paleontologia}

No que refere à presença da Paleontologia na Educação Básica Brasileira, a análise dos PCN revela uma abordagem superficial ou mesmo imprecisa do termo. Nos PCN para o Ensino Fundamental a Paleontologia é citada 4 vezes, 2 nos PCN referentes ao Ensino Fundamental I e 2 nos PCN referentes ao Ensino Fundamental II. Nos PCNEM, no capítulo sobre os objetivos dos conhecimentos de Biologia, tem-se: "Focalizando-se a teoria sintética da evolução, é possível identificar a contribuição de diferentes campos do conhecimento para a sua elaboração, como, por exemplo, a Paleontologia, a Embriologia, a Genética e a Bioquímica. São centrais para a compreensão da teoria os conceitos de adaptação e seleção natural como mecanismos da evolução e a dimensão temporal, geológica do processo evolutivo" (Brasil 2000). Esta é a única vez que aparece a Paleontologia no documento que regulava os currículos do Ensino Médio. É importante ressaltar a ausência no texto da definição de Paleontologia como a ciência que estuda os fósseis.

$\mathrm{Na} \mathrm{BNCC}$, cujo texto completo com 600 páginas foi homologado em dezembro de 2018, encontram-se, entre os conteúdos previstos para a unidade temática Terra e Universo - para o $6^{\circ}$ ano do Ensino Fundamental - habilidades que se referem à "identificação de diferentes tipos de rochas, relacionando a formação de fósseis a rochas sedimentares em diferentes períodos geológicos". Ao apontar as competências específicas para a área de Ciências da Natureza e suas Tecnologias no Ensino Médio, o texto da BNCC descreve "analisar e utilizar interpretações sobre a dinâmica da vida, da Terra e do Cosmos para elaborar argumentos, realizar previsões sobre o funcionamento e a evolução dos seres vivos e do Universo, e fundamentar e defender decisões éticas e responsáveis". E, na sequência do texto "Nessa competência específica, podem ser mobilizados conhecimentos conceituais relacionados a: origem da Vida; evolução biológica; registro fóssil; exobiologia; biodiversidade; origem e extinção de espécies...”. Com exceção para os combustíveis fósseis, essas são as únicas citações sobre fósseis na BNCC. O texto não faz menção sobre a Paleontologia como a ciência que estuda os fósseis e nem a menciona relacionada a outros conteúdos, como anteriormente nos PCN (Brasil 2018).

A maneira superficial e imprecisa como tem sido abordada a Paleontologia nos documentos oficiais se reflete nos livros didáticos brasileiros. De fato, Moraes et al. (2007) analisaram 34 livros didáticos comparando-os com a abordagem sugerida pelos PCNEM. As autoras concluíram que a maioria dos livros didáticos apresenta os temas da Paleontologia conforme recomendam os PCNEM, porém falta clareza nessa abordagem uma vez que os próprios PCNEM também carecem de precisão para relacionar a Paleontologia com os conteúdos que lhe são pertinentes.

Mais recentemente, Alonço \& Boelter (2016) realizaram uma investigação semelhante e encontraram temas como conceito de fósseis, processos de fossilização, datação de fósseis, tempo geológico, deriva continental, estudo dos dinossauros, comportamento e adaptação de espécies entre outros, intimamente relacionáveis à ciência paleontológica. No entanto, segundo os autores: "...todos os conteúdos estão associados a outros capítulos, principalmente à Origeme Evolução da Vida na Terra. Assim, percebe-se que é necessário repensar a forma de abordar a Paleontologia nos livros didáticos, tornado esse conteúdo não somente uma ferramenta e sim que a Paleontologia seja um dos principais eixos que auxiliam na explicação sobre a Origem e Evolução da Vida na Terra" (Alonço \& Boelter 2016).

Assim, apesar de temas diretamente ligados à Paleontologia estarem presentes tanto nos PCN 
quanto nos livros didáticos adotados na Educação Básica Brasileira, a ausência quase completa das relações explícitas dos referidos conteúdos com a Paleontologia parece ser uma das causas responsáveis pelo desconhecimento dessa ciência por parte dos estudantes.

\section{O Parque Paleontológico de Itaboraí (PPI)}

O PPI localiza-se entre as coordenadas $22^{\circ} 50$ '26,46”' S e 42 52' 43,89” W no município de Itaboraí (RJ), distante aproximadamente $60 \mathrm{~km} \mathrm{da}$ capital Rio de Janeiro (Figura 1).

Bergqvist et al. (2008) descrevem a história pregressa do PPI, atualmente uma Área de Preservação Permanente - cujo principal intuito é de preservar os testemunhos da Geologia e os fósseis remanescentes, bem como possibilitar o acesso destes acervos aos visitantes - desde 1928, com a descoberta da Bacia Calcária de São José de Itaboraí até os dias atuais.

Entre os macrofósseis encontrados em Itaboraí, Bergqvist et al. (2005) destacam que os mamíferos são o grupo de maior predominância e diversificação, seguidos pelos moluscos, répteis, aves, vegetais e anfíbios. Os fósseis de gastrópodes foram coletados na camada de calcário cinzento que preenche o fundo da bacia, embora nessa camada fossem encontrados também alguns vertebrados. Os fósseis de mamíferos, de plantas, anfíbios, répteis e aves, em sua maioria, foram coletados nos sedimentos que preenchem os canais de dissolução e as fendas que cortam verticalmente os calcários cinzentos e travertinos. Oliva (2018) fez uma descrição detalhada desses achados e suas localizações. A Figura 2 apresenta um mapa geológico da Bacia de Itaboraí.

\section{Metodologia}

O público alvo consistiu de estudantes de 3 escolas públicas de Ensino Médio: Instituto Estadual de Educação (73 alunos, sendo 29 do $1^{\circ}$ ano, 36 do $2^{\circ}$ ano e 8 do 3 o ano), Escola Estadual Governador Juscelino Kubitschek ( 34 alunos do $3^{\circ}$ ano) e Colégio Estadual Francesca Carey (69 alunos, sendo 27 do $1^{\circ}$ ano, 17 do 2 o ano e 25 do 3 o ano). A faixa etária dos estudantes investigados estava correspondente à escolaridade sendo os números de meninos e de meninas aproximadamente equiparados. As 2 primeiras escolas situadas no Município de Juiz de Fora (MG) e a terceira escola situada no Município de Itaboraí (RJ). A escolha das escolas

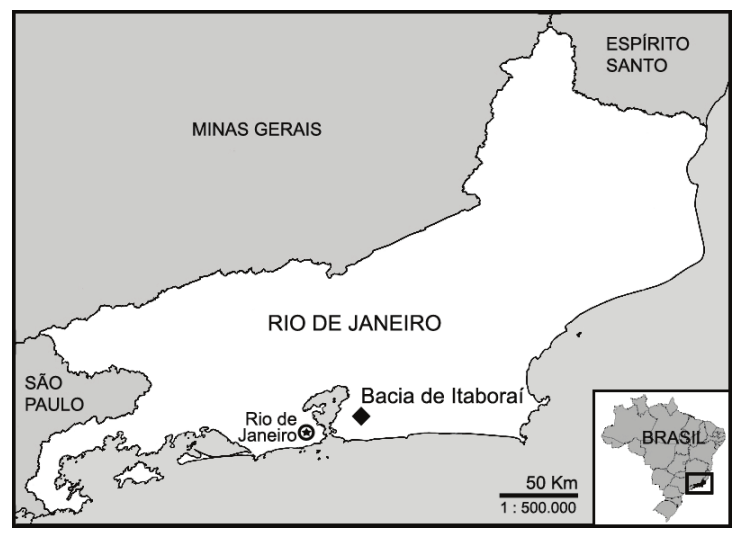

Figura 1. Localização da Bacia de Itaboraí no Estado do Rio de Janeiro. Fonte: https://bit.ly/2m4MPCy. Acesso 07.09.2019

do Município de Juiz de Fora se deu por 2 razões: inicialmente pelo fato de nesse município ainda não se registrar ocorrências de fósseis, estabelecendo assim um contraponto em relação aos estudantes de Itaboraí; a segunda razão diz respeito à facilidade do acesso às escolas por parte da equipe de pesquisadores envolvida no trabalho. A coleta dos dados foi realizada entre os meses de abril e junho de 2017.

O município de Juiz de Fora situa-se na região sudeste do Estado de Minas Gerais - Latitude $21^{\circ}$ 45' 51' S, Longitude 43 21' 01' W, mesorregião denominada como Zona da Mata. Geologicamente, a região está inserida no contexto do segmento central da Faixa da Ribeira gerada no Neo-

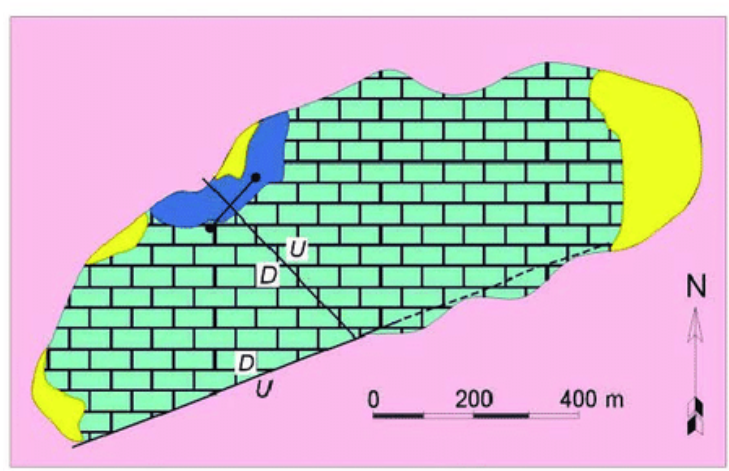

$2251^{\prime}$
Legenda:

Rochas do embasamento

ב. Depósitos de travertino Depósitos aluviais

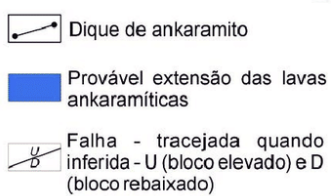
(bloco rebaixado)
Figura 2. Mapa geológico da Bacia de Itaboraí. Fonte: https://bit.ly/2IJt|6w. Acesso 07.09.2019 
-Proterozóico/Cambriano durante a Orogênese Brasiliana, na borda sul/sudeste do Cráton do São Francisco (Duarte 1998). Até o presente momento não há referência bibliográfica sobre a ocorrência de macrofósseis na região.

O município de Itaboraí situa-se na região metropolitana do Rio de Janeiro - Latitude: $22^{\circ}$ 44' 40" S, Longitude: $42^{\circ}$ 51'34" W e dista aproximadamente $220 \mathrm{~km}$ de Juiz de Fora. Em Itaboraí encontra-se a Bacia Sedimentar de José de Itaboraí, com ocorrência de fósseis do Paleoceno Superior (Bergqvist et al. 2005).

O percurso metodológico empregado nesse trabalho caracteriza-se, segundo critérios adotados por Kauark et al. (2010), como uma pesquisa aplicada, quali-quantitativa e exploratória. O instrumento utilizado foi um questionário envolvendo questões básicas sobre Paleontologia e fósseis. Por se tratar de uma pesquisa do tipo exploratória com um número limitado de integrantes não cabe, nesse trabalho, procedimentos de generalização, estando seus resultados limitados ao público investigado.

O questionário aplicado nas três escolas participantes foi elaborado com perguntas abertas e em múltipla escolha, cujos principais objetivos eram investigar às seguintes questões: (i) Qual o nível de conhecimento entre os estudantes investigados sobre Paleontologia e fósseis? (ii) A proximidade da escola do PPI favorece o conhecimento sobre Paleontologia e fósseis entre os estudantes?

Para a aplicação do questionário foi solicitada autorização junto à direção da escola. A apresentação do pesquisador e a aplicação do questionário ocorreram em aproximadamente 40 minutos, sendo esse tempo cedido pelo professor regente da turma. Os estudantes tomaram ciência de que o questionário fazia parte de um projeto de pesquisa desenvolvido a partir de uma colaboração entre a Universidade de Évora (UE), a Faculdade de Ciências e Tecnologia da Universidade Nova de Lisboa (FCT/UNL) e o Instituto de Química da Universidade Federal do Rio de Janeiro (IQ/ UFRJ). Na ocasião também ficou acordado que a participação deveria ser facultativa e não implicaria em qualquer recompensa ou punição decorrente da colaboração ou não do aluno.

A probabilidade de significância (p) das respostas dos grupos de alunos investigados foi calculada através do teste exato de Fisher, obtido a partir do software WinPepi versão 11.65 (Abramson 2011). Esse teste estatístico é usado quando todos os escores de duas amostras aleatórias independentes caem em uma ou em outra classe mutuamente exclusivas. Assim, todo sujeito em cada grupo manifesta um entre dois escores possíveis (Siegel \& Castelan 2006). Neste trabalho, a hipótese nula $H_{0}$ (Não há diferença estatística entre as respostas dos alunos de Juiz de Fora e de Itaboraí) foi testada para um nível de significância $(\alpha)$ de $5,0 \%$. Assim, quando $p>$ $\alpha$ mantêm-se $\mathrm{H}_{0}$ e, quando $\mathrm{p}<\alpha, \mathrm{H}_{0}$ é rejeitada.

\section{Resultados e discussão}

Inicialmente são analisados os livros didáticos e em seguida as respostas dos questionários aplicados. O Programa Nacional do Livro Didático para o Ensino Médio (PNLEM), implantado em 2004, prevê a universalização de livros didáticos para os alunos do Ensino Médio público de todo o país. Para Frison et al. (2009) o livro didático tem sido praticamente o único instrumento de apoio do professor e se constitui numa importante fonte de estudo e pesquisa para os estudantes. Argumentação semelhante com relação aos conteúdos relativos à Paleontologia foi apresentada por Sandrin et al. (2016).

Como verificado nos PCNEM, temas ligados à Paleontologia aparecem na disciplina de Biologia. Sendo assim, procedeu-se uma investigação de duas das principais coleções adotadas pelo Programa Nacional do Livro Didático para o Ensino Médio (PNLEM) no triênio 2015 - 2017, cada uma delas com 3 volumes. A primeira coleção, de autoria de Osório (2013a, 2013b, 2013c), intitula-se "Biologia Ser Protagonista" (coleção 1) e a segunda, de autoria de Bröckelmann (2013a, 2013b, 2013c), intitula-se “Conexões com a Biologia" (coleção 2). Na coleção 2 (volume 1), verificou-se, no organograma das subáreas da biologia, a seguinte definição do termo Paleontologia: Paleontologia - Estuda os Fósseis e no volume 3, dessa mesma coleção, na seção "Uma profissão: Paleontólogo" - "A Paleontologia é a ciência que estuda a história da vida da Terra com base nos registros fósseis" (coleção 2).

Em ambas as coleções o termo fóssil aparece principalmente no volume 3, no capítulo sobre evolução da vida e sem associação à Paleontologia, como destaca-se:

"Fósseis (do latim fossilis, "extraído da terra") são restos ou vestígios de serres vivos que se preservaram por milhares de anos.” (coleção 1, volume 3, p.139).

"Registro fósseis indicam que os organismos eucariontes surgiram há mais de 2 bilhões de anos" (coleção 2, volume 3, p.136).

\begin{tabular}{c|c|c|c|c|c}
\hline C Terrae Didat. & Campinas, SP & v.15 & $1-8$ & $\mathrm{e} 019034$ & 2019 \\
\hline
\end{tabular}


Constata-se assim uma quase ausência da Paleontologia nessas coleções didáticas adotadas no Ensino Médio público brasileiro.

Numa pesquisa recente, Alonço \& Boelter (2016) investigaram temas ligados à Paleontologia nos livros didáticos de biologia do Ensino Médio. Foram encontrados temas como conceito de fósseis, processos de fossilização, datação de fósseis, tempo geológico, deriva continental, estudo dos dinossauros, comportamento e adaptação de espécies entre outros, todos apresentados e discutidos a partir de Capítulos relativos à Origem e à Evolução da Vida na Terra. Segundo os autores, quando aparecia alguma menção à Paleontologia, essa era superficial e vaga.

Para a análise do questionário, optou-se por separar os grupos de alunos provenientes do Município de Juiz de Fora (Grupo A) dos alunos provenientes do Município de Itaboraí (Grupo B).

O questionário foi composto por 7 perguntas fechadas ou em múltipla escolha (Oliva 2018). Na primeira pergunta os estudantes foram questionados se já haviam aprendido algo sobre Paleontologia. Os resultados obtidos encontram-se resumidos na Tabela 1.

Da totalidade de respondentes foram obtidas $35,8 \%$ de respostas afirmativas. Quando as respostas são analisadas separadamente, responderam afirmativamente $14,0 \%$ dos estudantes do Grupo A e $69,6 \%$ dos estudantes do Grupo B. Essa diferença significativa $(p<0,05)$ de respostas afirmativas entre os 2 grupos sugere, a princípio, que a localização da escola nas proximidades do parque pode interferir no acesso ao conhecimento sobre Paleontologia, embora não se possa afirmar, a essa altura, sobre a profundidade do conhecimento nem sobre a fonte de onde os estudantes aprenderam sobre o tema. Aos alunos que responderam negativamente à pergunta 1 foi recomendado que passassem à pergunta 4 .

Na sequência foi indagado, na pergunta 2 , onde os estudantes aprenderam sobre Paleontologia. As respostas deveriam ser marcadas em uma ou mais das opções disponíveis numa lista. A Tabela 2 apresenta os resultados da pergunta 2. Da totalidade (132 opções marcadas), 31,1\% marcaram o professor; 16,7 \% marcaram televisão, $14,4 \%$ marcaram museu e $12,1 \%$ marcaram internet. Além disso, 15,9 \% marcaram a opção outros ou não responderam. Vale a pena ressaltar que o livro didático foi assinalado em apenas $2,3 \%$ das respostas. De fato, conforme constatado anteriormente nesse trabalho,

Tabela 1. Resultados referentes à pergunta 1 (Você já aprendeu alguma coisa, na escola ou fora dela, sobre Paleontologia?) e probabilidade de significância (p)

\begin{tabular}{c|c|c|c|c}
\hline Grupo & $\begin{array}{c}\text { Respostas } \\
\text { afirmativas } \\
\mathrm{N}-(\%)\end{array}$ & $\begin{array}{c}\text { Respostas } \\
\text { negativas } \\
\mathrm{N}-(\%)\end{array}$ & $\begin{array}{c}\text { Total } \\
\mathrm{N}-(\%)\end{array}$ & $\mathrm{p}$ \\
\hline A & $15(14,0)$ & $92(86,0)$ & $107(100)$ & \multirow{2}{*}{$<0,05$} \\
\hline B & $48(69,6)$ & $21(30,4)$ & $69(100)$ & \multirow{2}{*}{$<0,05)$} \\
\hline Total & $63(35,8)$ & $103(64,2)$ & $176(100)$ & \\
\hline
\end{tabular}

bem como na literatura (Alonço \& Boelter 2016), a Paleontologia está quase ausente dos conteúdos tratados na maioria dos livros didáticos do Ensino Médio ou é tratada de forma superficial. Em ambos os Grupos, o professor foi à opção mais assinalada.

$\mathrm{Na}$ terceira pergunta foi indagado o que é Paleontologia. Cada aluno foi incentivado a responder, mesmo não tendo uma idéia precisa do termo. As respostas foram classificadas em corretas ou incorretas. Foram consideradas corretas as respostas que fizeram menção à Paleontologia como a ciência que estuda fósseis, icnofósseis, formas de vida extinta, seres pré-históricos, vestígios de seres que habitavama Terra há milhões de anos, seres que viveram há mais de 10.000 anos atrás e qualquer relação explicita semanticamente correta. Podem-se destacar as seguintes respostas corretas:

"É o estudo dos fósseis (aluno108)",

"Matéria sobre os fósseis (aluno 115)"

"Encontrar e conhecer seres do passado que entraram em extinção (Aluno118).

Foram consideradas incorretas as respostas que não faziam menção aos fósseis e citavam seres do

Tabela 2. Resultados referentes à pergunta 2: Procure se lembrar de onde você aprendeu sobre Paleontologia. Você pode assinalar mais de uma opção.

\begin{tabular}{l|c|c|c}
\hline Opção & $\begin{array}{c}\text { Grupo A } \\
\mathrm{N}-(\%)\end{array}$ & $\begin{array}{c}\text { Grupo B } \\
\mathrm{N}-(\%)\end{array}$ & $\begin{array}{c}\text { Total } \\
\mathrm{N}-(\%)\end{array}$ \\
\hline Professor & $9(32,1)$ & $32(30,7)$ & $41(31,1)$ \\
\hline Museu/Parque & $\mathrm{xxx}$ & $19(18,3)$ & $19(14,4)$ \\
\hline Televisão & $4(14,3)$ & $18(17,3)$ & $22(16,7)$ \\
\hline $\begin{array}{l}\text { Conversa com } \\
\text { colegas }\end{array}$ & $\mathrm{xxx}$ & $10(9,6)$ & $10(7,6)$ \\
\hline Internet & $7(25,0)$ & $9(8,6)$ & $16(12,1)$ \\
\hline Livro didático & $3(10,7)$ & $\mathrm{xxx}$ & $3(2,3)$ \\
\hline $\begin{array}{l}\text { Outros/não } \\
\text { respondeu }\end{array}$ & $5(17,9)$ & $16(15,3)$ & $21(15,9)$ \\
\hline Total & $28(100)$ & $104(100)$ & $132(100)$ \\
\hline
\end{tabular}


presente, como por exemplo:

"Pesquisas arqueológicas de ossos (Aluno 61)"

"É um meio de trabalho onde você procura por restos mortais de seres através de escavações" (Aluno 63)

"É o estudo de fragmento de animais ou de humanos que viveram em uma certa região (Aluno 160)"

"Local onde as coisas antigas ficam" (Aluno 162)

A Tabela 3 apresenta os resultados das respostas dos alunos, onde se pode constatar que 87,0 \% de ambos os grupos definiram corretamente o que é Paleontologia. Quando analisadas as respostas separadamente, 72,7 \% dos alunos do grupo A e 91,4 \% dos alunos do Grupo B responderam corretamente. Esse resultado, aliado ao resultado da pergunta 1, pode sugerir que a localização da escola próxima ao PPI é um fator importante para o conhecimento entre os alunos dessa ciência.

Na pergunta 4 foi indagado aos estudantes se já ouviram falar ou se já estudaram sobre fósseis. $\mathrm{Na}$ totalidade, $88,1 \%$ responderam afirmativamente. Analisados os grupos A e B separadamente, os resultados de respostas afirmativas foram, respectivamente, $86,9 \%$ e $89,8 \%$. A Tabela 4 apresenta os resultados referentes à pergunta 4 . Os alunos que responderam negativamente à pergunta 4 encerraram o questionário.

Na pergunta 5, elaborada na forma de múltipla escolha, foi solicitado aos alunos que assinalassem a opção que melhor define um fóssil. As opções propostas foram: (I) um animal extinto, (II) uma pedra preciosa, (III) restos de vegetação provenientes de queimadas, (IV) restos de seres que viveram no passado e $(\mathrm{V})$ rocha de origem vulcânica. As respostas foram classificadas em corretas (opção IV) ou incorretas (opções I, II, III e V). Na totalidade, obteve-se 91,0 \% de respostas corretas, sendo 88,2 \% do Grupo A e 95,2 \% do Grupo B. A Tabela 5 apresenta os resultados.

A pergunta 6 teve como objetivo verificar o conhecimento dos estudantes sobre a ocorrência ou não de fósseis em seu município. A resposta mais frequente entre os estudantes de Juiz de Fora (Grupo A) foi "não sei” (73,0\%). Para os estudantes de Itaboraí (Grupo B), a resposta mais frequente foi $\operatorname{sim}(77,4 \%)$. Essa resposta é coerente uma vez que nesse munícipio está localizado o PPI, um importante meio de divulgação da Paleontologia entre a população. A Tabela 6 apresenta os resulta-
Tabela 3. Resultados referentes à pergunta 3 (Então, para você, o que é Paleontologia? Responda mesmo se você não tem uma idéia precisa) e probabilidade de significância $(p)$

\begin{tabular}{c|c|c|c|c}
\hline \multirow{2}{*}{ Grupo } & $\begin{array}{c}\text { Respostas } \\
\text { Corretas } \\
\text { N - (\%) }\end{array}$ & $\begin{array}{c}\text { Respostas } \\
\text { Incorretas } \\
\text { N - (\%) }\end{array}$ & $\begin{array}{c}\text { Total } \\
\text { N - (\%) }\end{array}$ & \multirow{2}{*}{$\mathrm{p}$} \\
\hline A & $8(72,7)$ & $3(27,3)$ & $11(100)$ & \multirow{2}{*}{0,138} \\
\hline B & $32(91,4)$ & $3(8,6)$ & $35(100)$ & \\
\hline Total & $40(87,0)$ & $6(13,0)$ & $46(100)$ & \\
\hline
\end{tabular}

Tabela 4. Resultados referentes à pergunta 4 (Você já ouviu falar ou estudou sobre fósseis?) e probabilidade de significância (p)

\begin{tabular}{c|c|c|c|c}
\hline \multirow{2}{*}{ Grupo } & $\begin{array}{c}\text { Respostas } \\
\text { afirmativas } \\
\mathrm{N}-(\%)\end{array}$ & $\begin{array}{c}\text { Respostas } \\
\text { negativas } \\
\mathrm{N}-(\%)\end{array}$ & $\begin{array}{c}\text { Total } \\
\mathrm{N}-(\%)\end{array}$ & $\mathrm{p}$ \\
\hline A & $93(86,9)$ & $14(13,1)$ & $107(100)$ & \multirow{2}{*}{0,368} \\
\hline B & $62(89,8)$ & $7(10,2)$ & $69(100)$ & \\
\hline Total & $155(88,1)$ & $21(11,9)$ & $176(100)$ & \\
\hline
\end{tabular}

Tabela 5. Resultados referentes à pergunta 5 (Para você o que melhor define um fóssil? Marque somente uma opção) e probabilidade de significância ( $p)$.

\begin{tabular}{c|c|c|c|c}
\hline \multirow{2}{*}{ Grupo } & $\begin{array}{c}\text { Respostas } \\
\text { corretas } \\
\mathrm{N}-(\%)\end{array}$ & $\begin{array}{c}\text { Respostas } \\
\text { incorretas } \\
\mathrm{N}-(\%)\end{array}$ & $\begin{array}{c}\text { Total } \\
\mathrm{N}-(\%)\end{array}$ & $\mathrm{p}$ \\
\hline A & $82(88,2)$ & $11(11,8)$ & $93(100)$ & \\
\hline B & $59(95,2)$ & $3(4,8)$ & $62(100)$ & \multirow{2}{*}{0,113} \\
Total & $141(91,0)$ & $14(9,0)$ & $\begin{array}{c}155 \\
(100)\end{array}$ & \\
\hline
\end{tabular}

Tabela 6. Quantitativo das respostas à pergunta 6 (Existem fósseis no município onde você mora?) e probabilidade de significância (p)

\begin{tabular}{c|c|c|c|c|c}
\hline Grupo & $\begin{array}{c}\text { Sim } \\
\text { N - (\%) }\end{array}$ & $\begin{array}{c}\text { Não } \\
\text { N - (\%) }\end{array}$ & $\begin{array}{c}\text { Não sei } \\
\text { N - (\%) }\end{array}$ & $\begin{array}{c}\text { Total } \\
\text { N - (\%) }\end{array}$ & p \\
\hline A & $14(15,0)$ & $11(12,0)$ & $68(73,0)$ & $93(100)$ & \\
\cline { 1 - 5 } B & $48(77,4)$ & $1(1,6)$ & $13(21,0)$ & $62(100)$ & \multirow{2}{*}{0,05} \\
\hline Total & $62(46,2)$ & $12(6,8)$ & $81(17,4)$ & $155(100)$ & \\
\hline
\end{tabular}

dos referentes a questão 6.

Questionamento semelhante foi feito por Heirich et al. (2015) sobre o conhecimento dos estudantes da educação básica no município de Tibagi (PR), local onde é relatada a ocorrência de fosseis de braquiópodes, bivaves e trilobitas da Formação Ponta Grossa - Membro Tibagi (Horodyski, 2010). Nesse trabalho, $19,9 \%$ (de um total de 236 alunos) 
responderam afirmativamente para ocorrência de fósseis no município de Tibagi.

$\mathrm{Na}$ pergunta 7 foi indagado aos estudantes se sabiam da existência de fósseis no Brasil e 87,1 \% do total de estudantes responderam afirmativamente, sendo 83,9 \% de Juiz de Fora e 90,3 \% de Itaboraí (Tab. 7). Duarte et al. (2016), fizeram o mesmo questionamento a estudantes da educação básica e encontraram $64,6 \%$ (de um total de 258 alunos) e Heirich et al. (2015) encontraram 58,0 \% (de um total de 236 alunos).

\section{Conclusões e considerações finais}

Esse trabalho teve como objetivo geral investigar o ensino de Paleontologia na Educação Básica Brasileira. Inicialmente, através da análise de duas importantes coleções de livros didáticos empregadas no Ensino Médio Brasileiro bem como do levantamento de trabalhos citados na literatura, constata-se que a Paleontologia - quando aparece nos referidos textos - é tratada de forma superficial, descontextualizada e desconectada da realidade e do cotidiano do aluno. Essa constatação é um reflexo dos PCN que não consideram a Paleontologia como um item de estudos, mas sim atrelada a outras disciplinas.

Foi investigada a possibilidade da proximidade da escola de um importante parque paleontológico ser capaz de influenciar os conhecimentos sobre Paleontologia entre os estudantes. A facilidade do acesso e a opção de se trabalhar a temática de forma relacionada ao dia-a-dia dos estudantes justificou a investigação dessa hipótese. Os resultados obtidos evidenciaram que o fato da escola se localizar às vizinhanças do parque e de promover frequentemente passeios de seus alunos a esse local influenciou no conhecimento sobre Paleontologia entre os estudantes. De fato, ao serem indagados se conheciam algo sobre Paleontologia, respostas afirmativas foram significativamente mais frequentes entre os estudantes de Itaboraí (Grupo B). Das 6 perguntas que permitiram a comparação entre os Grupos A e $B$ de alunos, duas apresentaram significância estatística e as restantes, embora sem significância estatística, apontaram na mesma direção de que os estudantes de Itaboraí possuem maiores conhecimentos sobre Paleontologia e fósseis. Tais resultados podem ser justificados mais pelo fato do PPI ser utilizado como área de lazer - tanto pelas escolas como pela população vizinha - do que constituir um espaço não formal sistemático com fins educacionais. De fato, visitas ao PPI são frequentemente organizadas
Tabela 7. Quantitativo das respostas à pergunta 7 (Existem fósseis no Brasil? ) e probabilidade de significância (p)

\begin{tabular}{|c|c|c|c|c|c|}
\hline Grupo & $\begin{array}{c}\text { Sim } \\
N-(\%)\end{array}$ & $\begin{array}{c}\text { Não } \\
\text { N - (\%) }\end{array}$ & $\begin{array}{l}\text { Não sei } \\
\text { N - (\%) }\end{array}$ & $\begin{array}{c}\text { Total } \\
\text { N - (\%) }\end{array}$ & $\mathrm{p}$ \\
\hline A & $78(83,9)$ & $1(1,1)$ & $4(15,0)$ & $93(100)$ & \multirow{3}{*}{0,086} \\
\hline B & $56(90,3)$ & $5(8,0)$ & $1(1,7)$ & $62(100)$ & \\
\hline Total & $134(87,1)$ & $6(4,5)$ & $5(8,4)$ & $155(100)$ & \\
\hline
\end{tabular}

pelas escolas vizinhas, no entanto, essas possuem o caráter exclusivo de um passeio, sem intenção de se trabalhar conteúdos curriculares, aspectos históricos ou científicos relacionados ao parque. Esse procedimento caracteriza uma subutilização de um local rico em potencialidades educativas capazes de reforçar o aprendizado dos conteúdos curriculares.

Esse conhecimento diferenciado dos estudantes de Itaboraí, ainda que superficial, pode ser aproveitado como um subsunçor capaz de ancorar novos e mais aprofundados conhecimentos acerca da Paleontologia, da Botânica, da Biologia e das disciplinas afins. Temas como tempo geológico, identificação de rochas, prospecção, coluna estratigráfica e identificação de fósseis podem compor uma ou mais sequências didáticas a serem elaboradas em trabalhos de campo com objetivos educacionais.

Como sugestão para o aproveitamento do PPI como um efetivo espaço não formal de educação, sugere-se uma agenda de visitas escolares elaboradas ao longo do ano letivo e com objetivos educacionais, para além de lazer e contemplação. Essa agenda envolve um amplo trabalho conjunto de toda a comunidade escolar e até mesmo de pais e responsáveis que desejarem participar. As práticas educativas em espaços não formais - tais como museus, parques, zoológicos etc - podem se constituir como potencialmente motivadoras para os estudos dos conteúdos da educação formal escolar (Oliveira et al. 2014). São previstas visitas prévias ao parque - sem os alunos - com objetivo de apropriação e adaptação do acervo aos conteúdos escolares. A seguir, atividades antes, durante e após as visitas são elaboradas no sentido de (i) reconhecer os interesses dos alunos; (ii) apresentar o local a ser visitado; (iii) minimizar o efeito surpresa; (iv) preparar a mediação para o momento da visita considerando as especificidades da educação em espaços não formais e (v) programar atividades posteriores que funcionem como um "feedback" e um reforço do aprendizado. De fato, um efetivo trabalho educativo em espaços não formais que auxilie a educação

\begin{tabular}{c|c|c|c|c|c}
\hline (C) Terrae Didat. & Campinas, SP & v.15 & $1-8$ & $\mathrm{e} 019034$ & 2019 \\
\hline
\end{tabular}


formal deve começar e acabar em sala de aula.

Numa acepção ampla, todas as disciplinas da grade curricular - a partir de uma adaptação dos conteúdos, considerando a escolaridade da turma visitante e o acervo disponível no parque - podem ser trabalhadas nas referidas visitas.

\section{Referências}

Abranson, J. (2011). Winpepi updated: computer programs for epidemiologist and their teaching potential. Epidemiologic Perspectives \& Innovations, 8(1): 1-9. URL: https://bit.ly/2BuYRJy. Acesso 21.11.2017.

Alonço, M.; \& Boelter, R. (2016). Paleontologia nos Livros Didáticos de Biologia do Ensino Médio. Revista da SBEnBio 9: 7671-7682.

Bergqvist, L.; Moreira, A.; \& Pinto, D. (2005). Bacia de São José de Itaboraí - 75 anos de História e Ciência. Biodiversidade de mamíferos fósseis brasileiros. Revista Geociências-UNG, 9(6): 54-68.

Bergqvist, L.; Rodrigues, M.; Rodrigues, B.; Perez, R.; \& Beltrão, M. (2008). Bacia São José de Itaboraí, RJ: berço dos mamíferos no Brasil. Sítios Geológicos e Paleontológicos do Brasil. In: Winge M, Schobbenhaus C; Souza C.; Fernandes A.; Berbert-Born M; Queiroz E. editores. Sítios geológicos e paleontológicos do Brasil. URL: www.unb.br/ig/sigep/sitio123/sitio123. pdf Acesso 10.05.2018.

Brasil. Ministério da Educação. Secretaria de Educação Fundamental. (1998). Parâmetros Curriculares Nacionais. Brasília: MEC/SEF. URL: https:/bit. ly/2NiPe9E. Acesso em 22.01.18.

Brasil. Ministério da Educação. Secretaria de Educação Média e Tecnológica. (2000). Parâmetros Curriculares Nacionais: Ensino Médio. Brasília. URL: https://bit. ly/2oMcgpe. Acesso em 22.01.18.

Brasil. Ministério da Educação. (2018). Base Nacional Comum Curricular. Brasília. URL: https:/bit. ly/2F39Opk. Acesso em: 17.12.18.

Brockelmann, R. (2013a). Conexões com a Biologia vol. 1. São Paulo: Ed. Moderna. 182p.

Brockelmann, R. (2013b). Conexões com a Biologia vol. 2. São Paulo: Ed. Moderna. 312p.

Brockelmann, R. (2013c). Conexões com a Biologia vol. 3. São Paulo: Ed. Moderna. 303p.

Duarte, B. (1998). Evolução tectônica dos ortognaisses dos Complexos Juiz de Fora e Mantiqueira na região de Juiz de Fora, MG: Geologia, petrologia e geoquímica. São Paulo: Universidade de São Paulo. 269p. (Tese de Doutorado).

Duarte, S.; Arai, M.; Passos, N.; \& Wanderley, M. (2016). Paleontologia no Ensino Básico das escolas da rede estadual do Rio de Janeiro: uma avaliação crítica. Anuário do Instituto de Geociências, 39(2): 124-132.
Frison, M.; Vianna, J.; Chaves, J.; \& Bernardi, F. (2009). Livro didático como instrumento de apoio para construção de propostas de ensino de Ciências Naturais. In: VII Encontro Nacional de Pesquisa em Ensino de Ciências, Florianópolis, Brasil. Anais... Florianópolis. URL:http://posgrad.fae.ufmg.br/posgrad/viienpec/ pdfs/425.pdf. Acesso 05.03.2018.

Heirich, C.; Matsumura, W.; Myszynski Jr., L.; Sedorko, D.; \& Bosetti, E. (2015). O aprendizado da Paleontologia no Ensino Básico da cidade de Tibagi - PR. In: Reunião Anual da Sociedade Brasileira de Paleontologia - PR/SC, 2015, Dois Vizinhos. Anais Paleo 1: 42-46.

Horodyski, R. (2010). Tafonomia dos invertebrados fósseis na sequência Eifeliana-Frasniana da sucessão devoniana da sub-bacia de Apucarana, Bacia do Paraná, Tibagi$P R$, Brasil, Porto Alegre: Instituto de Geociências. UFRS. 91p. (Dissert. Mestrado).

Kauark, S.; Manhães, F.; \& Medeiros, C. (2010). Metodologia da pesquisa: um guia prático. Itabuna: Via Litterarum Ed. 86p.

Moraes, S. D.; Santos, J.; \& Brito, M. D. (2007). Importância dada à Paleontologia na educação brasileira: uma análise dos PCN e dos livros didáticos utilizados nos colégios públicos de Salvador, Bahia. In: Carvalho I. et al. 2007. Paleontologia: Cenários da Vida vol. 2. Rio de Janeiro: Interciências. p. 71-75.

Oliva, E. (2018). Ensino da Paleontologia em espaços não formais. Évora: Universidade de Évora/ Universidade Nova de Lisboa. 105p. (Dissert. Mestrado). URL: https://bit.ly/2BtNuSc. Acesso 13.11.2018.

Oliveira, G.; Turci, C.; Teixeira, B.; Garrido, I.; \& Moraes, R. (2014). Visitas guiadas ao Museu Nacional: interações e impressões de estudantes da Educação Básica. Ciência \& Educação, 20(1): 227-242.

Osorio, T. (2013a). Ser Protagonista: biologia, 1o ano: Ensino Médio, vol.1. São Paulo: Edições SM. 320p.

Osorio, T. (2013b). Ser Protagonista: biologia, 2ano: Ensino Médio, vol. 2. São Paulo: Edições SM. 320p.

Osorio, T. (2013c). Ser Protagonista: biologia, 3o ano: Ensino Médio, vol. 3. São Paulo: Edições SM. 311p.

Sandrin, M.; Puorto, G.; Nardi, R. (2016). Serpentes e acidentes ofídicos: um estudo sobre erros conceituais em livros didáticos. Investigações em ensino de ciências, 10(3): 281-298.

Schwanke, C.; \& Silva, M. (2004). Educação e Paleontologia. In: Carvalho I. S. (Org.). Paleontologia. Rio de Janeiro: Interciência, p. 123-130.

Siegel, S.; \& Castellan, N. (2006). Estatística não paramétrica para ciências do comportamento. Porto Alegre: Artmed. $448 \mathrm{p}$.

Werthein, J.; \& Cunha, C. (2005). Educação científica e desenvolvimento: o que pensam os cientistas. Brasília: UNESCO/Instituto Sangari. Representação no Brasil. $223 \mathrm{p}$. 